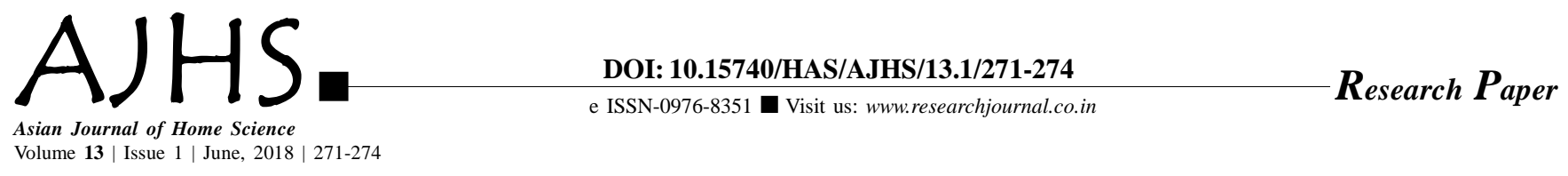

\title{
Sustainable development through women entrepreneurship
}

Mamta Tiwari and Gunjan Sanadya

Received: 07.11.2017; Revised: 11.04.2018; Accepted: 01.05.2018

See end of the paper for authors' affiliations

\section{Mamta Tiwari}

Agriculture University, Kota

(Rajasthan) India
-ABSTRACT : Entrepreneurship brings Economic empowerment which can only be possible through dissemination of relevant technologies of self employment and development of skill on recent and viable vocation, which can be an aid to rural development and can provide opportunities towards entrepreneurship development among rural youth.According to Kuratko (2011), entrepreneurship is defined as a "dynamic process of vision, change, and creation that requires an application of energy and passion towards the creation and implementation of new ideas and creative solution". Entrepreneurs may be defined as individuals who bring about an improvement, both for other individuals and for the society as a whole (Gorji and Rahimian, 2011). Longenecker et al. (2003) define entrepreneurs as individuals who discover market needs and launch new firms to meet those needs.Facilities and technical expertise are available at the center to train the farm woman, rural youth, school dropouts and extension functionaries for enhancement of the productivity of the crops of the area and its processing. This center offered every year many training programme varying from one day, three days short training to 40 days and 50 days vocational training programmes on Food Processing and Value Addition, fruits and vegetable preservation, handicrafts sewing, embroidery, organic farming and propagation of fruit plants, agricultural engineering, animal production, drudgery reduction and dairy etc. Many educational and vocational training programme conducted specially for rural women and consequently approximately 5000- 6000 youth were trained by the center in a year. Necessary infrastructure and expertise have been developed at center. Vocational trainings on different aspects processing and value addition of food products, fruits and vegetables preservation, establishment of vermin compost unit, handicrafts, nursery management, bee keeping, garment construction and designing and dairy were conducted at Krishi Vigyan Kendra Kota, Rajasthan, India in the year 2014-2015. Trainings on these aspects were given many times to different trainees to give equal chance to all participants. Extremely interested trainees could attend the trainings twice or thrice to become perfect in one stream. Total participants of vocational trainings during the year 2014-15 were 230 . After a year, the impact of these trainings were judged according to their performance, rate of self employment and amount of earnings.It could be evaluated through the study that rural youth were deeply motivated during all the trainings, developed skill and keen to start with some vocation just after the completion of training. They immediately formed self help groups and started working. Out of 230 trainees 115 were started their own vocation according to feasibility of row material, climate, market demand and family support. Majority of female youth were found engaged in processing and value addition of food products, fruits and vegetable preservation, soft toy making. Female preferred the vocation of garment construction and designing along with food processing independently. Similarly majority of them found handicrafts articles suitable for them as artificial jewellery, wall hanging and file covers making. 